\title{
IMPACT OF FAKE NEWS AND MYTHS RELATED TO COVID-19
}

\author{
Dr. Robin kabha \\ Assistant Professor, College of Mass Communication \& Public Relations \\ University of Fujairah, Fujairah - UAE \\ Dr. Ahmed Mostafa kamel \\ Assistant Professor, \\ Al Falah University, Dubai, \\ UAE \\ Dr. Moataz Elbahi \\ Assistant Professor, College of Mass Communication \\ Al Falah University, Dubai, \\ UAE \\ Dr. Abdu Mohamed Dawood Hafiz \\ Assistant Professor, College of Mass Communication \& Public Relations \\ University of Fujairah, Fujairah \\ UAE \\ Dr. Wided Dafri \\ Assistant Professor, \\ Al Falah University, Dubai, \\ UAE
}

\begin{abstract}
With the advent of the internet and the subsequent increase in use and accessibility, the social media networks have particularly emphasised in terms of the news being shred online. However, this has caused a drastic change in the assessment and obtaining of the real information. Hence, this paper has aimed to assess the impacts of fake news and myths regarding the novel Covid-19 pandemic. Through the systematic review of the related studies and support through relevant literature, the findings of the research include various harmful impacts of the notion. This ranges from small impacts such as spread of misinformation to more sinister impacts such as the wrongful utilisation of drugs for curing the disease. Moreover, the paper also mentions the various motives behind the spread of such false information, primarily fuelled by collecting monetary benefits in terms of digital marketing, etc. Overall, the study concludes the impacts of spread of fake news and myths are generally harmful to the public at large. In addition, some recommendations for future hedging against the notion and future studies have also been make.
\end{abstract}

Keywords: Fake News, Myths Impact , COVID-19 Pandemic News, Novel COVID-19

\section{INTRODUCTION}

In the era of new media, the rapid dissemination of news and information has allowed more Internet netizens and hot followers to have commentaries (Pulido et al., 2020). The rigor of news is essential. In the era of new media, the media for information dissemination is very abundant, so people receive news. The speed is quite fast and the accessibility is abundant. However, the segregation between what is actually a fact and what is being fabricated has become even more difficult (Groza 2020). The passing off of false information through the multiple media networks is becoming easier and more volatile in the recent past. This paper will maintain focus towards the element of the corresponding impact of fake news in the media, more particularly in light of the recent false information regarding the novel coronavirus (Covid-19) pandemic.

\section{Background and Rationale}

New media has a stronger ability to perceive emergencies. In recent years, many hot events in society have been spread through new 
media (Groza 2020). For example, "Take the Most Beautiful Secret, Eight Years of Concern" as an example, the incident After being reported by new media, it quickly spread on the Internet and attracted people's attention. After the incident was reported by "South Lake Report" in May 2016, it caused a strong response in the society. After investigation and research, it was found that the news was a false report. Similarly, there has been generally numerous false reporting related to the Covid-19 pandemic; from treatment methods to the number of cases in various regions all across the globe (Poudel et al., 2020; Calvillo et al., 2020). However, some of the fake news tends to have more sinister and congealing effects as compared to others. Hence, it is necessary to effectively explore these various impacts on the general population and analyse the overall impacts the false information tends to create in light of such news.

\section{Aim and Scope of Research}

This paper is primarily a desk-based research, which will include various secondary sources in order to support the arguments being presented. However, quantitative arguments will also be presented in a systematic manner in order to appraise the findings of the research. Moreover, several authentic data bases and research papers will be included for the study, in addition to news articles by approved sources. The paper will aim to evaluate the impacts of fake news and myths circling around the information related to the novel Covid-19 disease. In addition, in order to support the arguments of the paper, relevant research will also be used.

\section{LITERATURE REVIEW}

Since the start of the COVID-19 flare-up, the world has seen developing pressure from the pandemic component of a sickness with extreme epidemiological effects and widearriving at sociocultural and political side projects. In ideal states of public correspondence, the specialists would be lined up with an absolutely straightforward framework providing plentiful data and simplicity of comprehension to create believability, certainty, and organization with the media. In the rests of worthy renditions and amidst vagaries, people become their own specialists, burning-through phony news and repeating misleading danger stories with appalling outcomes. The article examines different parts of phony news and the utilization of open explanation by open specialists, referring to the instance of Iran and drawing matches with the ant vaccination development and its results. The creators address the test of composed direction of society with data, rivalling pseudo-logical pastiches that multiply dangerously fast without authentic information. This brings up the accompanying issue: which correspondence models ought to back the official account to make the conditions for joint effort and association with the media? What effects would such models have on the multiplication of misdirecting stories that residents go to during emergencies of fitting direction? The creators presume that it is likewise the public authority's part to utilize its wide perceivability to make references of security under the power of informative explanation, delicate to society's authentic inquiries and concerns. So, government should deliver dependable references on a stupendous scale, arranged by the morals of responsibility in accordance with the benefit of everyone.

\section{RESEARCH METHODS}

This paper has used the desk research method, which is primarily a secondary qualitative research methodology. External information mainly comes from various external information sources such as governments, international organizations, industry associations, chambers of commerce, banks, research institutions, consumer organizations, and libraries. The advantages of desk research are mainly that it saves time, effort, and cost. However, since the second-hand information was originally collected for other purposes, it has certain limitations when used for a specific purpose. This is manifested in the difference between the original collection methods (samples, data, collection tools, etc.), time, etc. of the data and the requirements of the research topic. Therefore, researchers must pay attention to judging its validity when using second-hand data. Desk based research is essentially an extension of literature review in a systematic manner. Literature review is the process of systematically reviewing and analysing various documents related to a certain research problem to understand the research status of the field. In other words, it is a process of systematically identifying, 
searching, investigating and summarizing the literature related to our research.

In fact, literature review is a complete process that includes both searching, reading and analyzing the literature, as well as summarizing, summarizing and commenting on these documents. The core issue in the literature review is the selection of references. This depends not only on the number of documents, but more importantly, including the most important and classic writings and the latest and valuable research results, and can analyse and summarize the deficiencies and existing problems of previous studies. The literature review will share the research results related to this research with readers, and can conduct academic dialogues on related issues beyond time and space. At the same time, it also provides a benchmark for comparison with other results. Hence, this study will employ the use of systematic literature review and desk based research to articulate the various findings for the paper.

\section{FINDINGS AND DISCUSSIONS}

\section{Clarifying Fallacy in News and Information}

"True" is the first principle of news reports. News media practitioners must convey the people's correct values through true reports and ensure that news reports truly reflect reality. At this stage, the ideological, public opinion, and ideological fields are showing a diversified development trend, which requires journalists to clarify fallacies, distinguish right from wrong, abide by professional ethics, and use their own actions to resist "fake news." At present, we have entered the era of "Internet $+"$. The rapid development of new media technology has brought great convenience to our lives, and has brought about earth-shaking changes in the way of information dissemination. The popularity of self-media platforms has brought many unverified fake news into the public's field of vision, and the resulting negative energy will affect the psychological environment of the people.

Specifically, the reasons for fake news in daily news reports are mainly reflected in the following aspects: First, journalists lack a sense of responsibility and morality and are eager for quick success in their work. The scientific and ethical literacy and work ability of TV station staff are uneven, and some reporters have the problem of "listening and believing" in their work. Writing manuscripts without conducting detailed investigations of news events or news figures often results in huge differences between manuscripts and actual facts. If the editor does not carefully review the manuscript at this time, "fake news" will appear. Therefore, to eliminate fake news, we must first strengthen the training of talents, improve the professional quality of reporters and editors, and strengthen the political control of news articles.

Secondly, the self-discipline mechanism has defects. TV stations need to establish strict work processes in news gathering, editing, and reporting. They should also establish a system of accountability for fake news. Only in this way can the living space of "fake news" be compressed and the industry environment can be purified. However, in actual work, it is difficult for reporters and editors to do this. Most TV stations are trying to standardize the work process of collecting, editing and reporting. However, due to the inadequate implementation of some systems, many fake news are still used. Finally, in order to pursue a sensational effect and increase the ratings, some TV stations will also hype some "small events" and "small news", and even have the problem of making fake news to cater to the preferences of the audience. News programs can learn from the advantages of self-media platforms, but the censorship of news information should be strengthened to prevent fake news.

\section{Reasons and Impacts of Fake News}

First of all, fake news can cause wrong public opinion orientation, which in turn causes social harm (Pennycook et al., 2020). TV news reports have the role of guiding public opinion, and if fake news appears in news programs, it will not only waste viewers' time and energy, reduce their emotional experience, but also hurt the feelings of the masses, and they will feel that they have been deceived. In turn, it is misleading in thinking and behaviour. If this problem is not effectively resolved, it will affect the healthy and harmonious development of society and increase social instability (Calvillo et al., 2020). Secondly, fake news leads to infringements, which in turn causes economic losses to television stations. Fake news violates the principle of authenticity of news reports, so it is easy to cause infringement incidents, and 
then cause unnecessary lawsuits to the program group and the TV station (Ahmed et al., 2020).

News practitioners who report fake news often need to compensate the victims, and serious ones may be held criminally responsible (Ahmed et al., 2020). This is something that all colleagues do not want to see. Therefore, we must try our best to eliminate fake news. In the end, fake news damages the image of the TV station, and fake news will cause damage to the image of the party or government to a large extent. News should be the microphone of the party and government's policies and proposals. Government departments need to rely on news programs to carry out ideological and political work for the entire society (Sahoo et al., 2020). Therefore, news actually represents the voice of the country. If fake news is not contained, it will not only affect the credibility of government departments, but also damage the image of TV stations(Islam et al., 2020).

New York University scholar Matthew Stanley, who has studied the history of science for many years, believes that when verifying fake news, use as many illustrations or diagrams as possible to make it easier for readers to understand the rationale behind. Some people are less willing to think or analyze (Roy et al., 2020). We need more communication methods and skills for these people. The BBC believes that in the information explosion period, readers usually judge the authenticity of the news based on intuition(Van Bavel et al., 2020). A 2012 study by Erin Newman, a lecturer in psychology at the Australian National University, has found that adding pictures to news can increase the credibility of readers(in O'Connor et al., 2020). The same principle, the use of descriptive language and vivid personal stories also make the news credible. Studies have also pointed out that people with low cognitive reflex test scores, that is, people who tend to make judgments based on intuition, are more likely to misbelieve rumors, regardless of their IQ (Van Bavel et al., 2020).

Under the influence of the rapid spread of Internet technology, domestic public opinion has shown a very active field situation, but it also faces an increasingly complex and diversified situation. Among them, the most far-reaching impact is that individuals attempt to interfere with the normal public opinion orientation of society by spreading false news (Ho et al., 2020). They are trying to open up a second field of public opinion and want to sing the opposite of the mainstream public opinion field (Sahoo et al., 2020). Impact of the new media era news media industry caused by subversive when it comes to innovative technology, but also involves the changing attitudes. Journalists must establish correct new media thinking, face up to the advantages of new media communication, grasp the characteristics of news communication in the new media era, raise the requirements for manuscripts, and eliminate fake news(O'Connor et al., 2020; Van Bavel et al., 2020).

It is necessary to emphasize the interactivity and timeliness of news dissemination in order to win the recognition of the audience (Roy et al., 2020). In addition, it should change its own positioning, respect the main position of the public in news communication, and clarify the role of its own communication guide. The requirements for the quality and authenticity of manuscripts should not be lowered in order to cater to the "tastes" of the audience (Rovetta et al., 2020). TV news programs in the new media era must be reformed, but they should learn from their strengths and advantages and should not "put the cart before the horse. It is necessary to go to the front line and accurately understand the needs of the masses. Show the focus events that the audience pays attention to in a new way, shorten the distance between news reports and the audience, and give the people the correct direction of public opinion (Xiong et al., 2020).

Some people who spread false news are simply misled, while others are driven by profit. fAnother way to profit from fake news is advertising revenue(Van Bavel et al., 2020). Giovanni Zagni, director of Facta, a newly established fact-checking website in Italy, said that about half of the false information that people see is about trying to create a virus or the like in order to get clicks, but after clicking it, it is a whole It is a Google advertising website. Zagni also mentioned that since its launch on April 2, about $90 \%$ of the content on the Facta website is about COVID19(Xiong et al., 2020). Scholars from Nanyang Technological University in Singapore 
conducted an analysis based on the data provided by the Singapore Science and Technology Research Agency (Kadam et al., 2020). The preliminary results found that since January, users worldwide have posted more than 100 million posts related to the new crown epidemic on the social networking site Facebook, sharing, liking or the number of opinions expressed exceeded 14 billion times. Among them, local Facebook users in Singapore have posted 80,000 related posts, sharing, liking or commenting more than 50 million times. In terms of Twitter, users worldwide have posted 3,300 related tweets, and the number of tweets by local users in Singapore has exceeded 80,000. The survey pointed out that most of the posts circulating on social networking sites did not come from official channels. Reposters of false information care more about likes than truth (Cinelli et al., 2020)

\section{Fake News and Myths in Covid-19}

Some Facebook posters claimed that COVID19 is not a new disease, and that false information about cattle or canine coronaviruses spread through Twitter. These misleading remarks about whether it is safe to eat animal protein have confused producers and consumers (O'Connor et al., 2020). The COVID-19 pandemic and the subsequent challenges to public health and the risk of economic downturn have spread false information and confusing statements around the world. In the face of many speculations and false news, scientific facts are the most important: the coronaviruses infected by animals are indeed different from the new viruses that currently infect humans (Ho et al., 2020). Researchers from all walks of life are studying whether livestock and poultry may be infected with any form of mild infection, or even carry the virus mutation that causes COVID-19, but so far there is no such evidence (Islam et al., 2020).

In other words, the coronavirus is a general term for a large group of viruses that spread widely in nature (Ahmed et al., 2020). Since the coronavirus covers a wide variety of viruses, such a rich variety of viruses has become a fertile ground for rumours, and it also brings additional challenges to dispel these rumours: unprovoked guesses, inaccurate information and false news (Pulido et al., 2020). False news in multiple languages spread on various social networking sites, claiming that the new coronavirus disease is not a new disease (Naeem et al., 2020). Photographs of preparation bottles of coronavirus vaccines for animals were also published as "evidence".

These claims are unreasonable. It must be pointed out that the official name of the virus that causes COVID-19 is SARS-CoV-2. The corona virus that can be prevented by the bovine vaccine is $\mathrm{BCV}$ or $\mathrm{BCoV}$; and the virus that causes canine infection is $\mathrm{CCV}$ or CRCoV(Palade et al., 2020). These coronaviruses are also not will not cause infection of other species. "The same is true for poultry. For example, for many years, Boehringer Ingelheim Animal Health has produced vaccines that protect poultry from infection by the gamma coronavirus of infectious bronchitis. Another false news widely circulated on social media claims that humans can contract the new coronavirus through direct contact or eating chicken products(Roy et al., 2020). This is another piece of false information with no scientific basis: the $\gamma$-coronavirus that causes chicken infection cannot be transmitted to humans. More needs to be pointed out that, according to a new study 1 has been proved that even humans infected with the pathogen COVID-19, which is subordinate to the $\beta$ coronavirus of SARS-Cov-2, due to the coughing or sneezing and spread in the air particles cannot infect chickens $\left(\mathrm{O}^{\prime}\right.$ Connor et al., 2020).

There is currently no information on the survival of the novel coronavirus on the surface of food, but the possibility of transmission of the virus through fresh bread, or other types of food is unlikely, as the mode of transmission is mainly through droplets containing secretions, respiratory (droplets) or by contact(Roy et al., 2020). There is no scientific evidence that hot air hand dryers are capable of killing the new coronavirus. To protect yourself from infection, the safest method is to wash your hands often with soap and water or an alcohol-based solution. After cleaning your hands you need to dry them thoroughly (Apuke et al., 2020).

There is currently no evidence that dogs and pets in general can transmit the coronavirus. Bleach should absolutely not be used to disinfect the paws of dogs after 
returning from a walk, even if very diluted in water (Pulido et al., 2020). When you return home it is advisable to ensure its hygiene by first cleaning the paws with products without added perfume (e.g. water and neutral soap) and then drying them well. Aggressive products or alcohol-based products should not be used because they can induce irritation, causing itching (Pennycook et al., 2020). Instead, the coat should be brushed and then wiped with a damp cloth. Taking a hot bath does not prevent the development of COVID-19. This eliminates any viruses present on the hands and does not run the risk of infections that could occur when touching the nose, mouth and eyes.The use of disinfectants, for example containing $70 \%$ alcohol or $0.1 \%$ chlorine-based (bleach), is sufficient to kill the virus on surfaces, nullifying its ability to infect people(Pulido et al., 2020). Mixing several products together thinking of getting a more powerful one against the coronavirus can be very harmful because it exposes you to dangerous products that can form during mixing and can lead to serious poisoning (Pennycook et al., 2020).

Before arriving in pharmacies, a drug must have passed several stages of experimentation that test its effectiveness, quality and safety following well-defined procedures(Pennycook et al., 2020). Only after it has passed all the experimental stages, and has been authorized by the competent authorities, can it be available in pharmacies and can be purchased after a doctor's prescription.A person who has contracted the new coronavirus can recover completely without having more traces of the virus in their body(Calvillo et al., 2020). So being positive for the new coronavirus does not mean staying infected forever.The symptoms of Covid-19 are generally mild and in this case they do not prevent moderate activities. Furthermore, the best and scientifically proven way to confirm if you have Covid-19 is with a laboratory test and not through apnea tests or breathing exercises.Frequent consumption of alcohol or spirits does not protect against new coronavirus infection (Ahmed et al., 2020). Alcohol is bad for health and addictive. Their consumption not only does not protect against the virus but exposes you to the risk of developing serious diseases, including cancers. To prevent contagion, you must stay at home, respect social distancing measures (at least 1 meter away from other people) and wash your hands frequently with soap and water or alcohol-based solution for at least 40-60 seconds (Calvillo et al., 2020).

Mixing several products together without knowing their effects is dangerous, as toxic substances could be generated by contact and inhalation (Ahmed et al., 2020). Remember that the most effective actions to prevent new coronavirus infection are: wash your hands frequently with soap and water or $70 \%$ alcohol-based solutions (ethyl alcohol / ethanol) for at least 40-60 seconds, scrubbing them well in all their parts; coughing or sneezing into the crook of the elbow or into a disposable tissue to be thrown away immediately after use; respect the measures of social distancing (distance of at least 1 meter from people)(Ho et al., 2020). There is no evidence that the flu vaccine facilitates contagion with the new coronavirus. These are two different viruses. The flu vaccination avoids contracting the seasonal flu virus and therefore has a double advantage: it facilitates the distinction between the two diseases (flu and COVID-19) and protects people at risk of developing severe forms of $\mathrm{flu}\left(\mathrm{O}^{\prime} \mathrm{C}\right.$ onnor et al., 2020).

Vitamin $C$ does not prevent you from being infected. On the other hand, says infectologist Antônio Bandeira, who is director of Epidemiological Surveillance in the State of Bahia, Vitamin C helps prepare the body to better face the virus, as well as physical exercise and a good night's sleep. Flag suggests that especially elderly people take Vitamin $\mathrm{C}\left(\mathrm{O}^{\prime}\right.$ Connor et al., 2020). One of these shared messages contains details of an alleged article written by a medical researcher who moved to Wuhan, China, the epicentre of transmissions of the new coronavirus, and who made observations on the topic. Among them is that the virus cannot resist heat and that temperatures of 26 and 27 degrees already kill it. "If this were true, the virus would not be alive in our body, which has a medical temperature of 36 degrees", stresses infectious disease physician Jaime Rocha, vice president of the Paraná Society of Infectology(Van Bavel et al., 2020; O'Connor et al., 2020).

The message also provides information about the evolution of the disease, and that it causes dry cough, runny nose and pneumonia 
(Apuke et al., 2020). Health authorities are reporting that suspicious cases of the new coronavirus are considered to be those who have fever and at least one respiratory sign or symptom (cough, difficulty breathing, throat pain, nasal congestion, headache, malaise, body pain) and who traveled to the following countries in the last 14 days before signs and symptoms appeared. For the treatment of infections caused by the new coronavirus, rest, consumption of plenty of water and medications to relieve symptoms, such as pain and fever, are indicated (Poudel et al., 2020). Depending on the course of the disease, other measures may be used. Health authorities are also guiding patient isolation, but it is happening at home, both in suspected cases and in confirmed cases in Brazil.The message mentioned in this article from Saúde Debate still brings it is important to wash your hands frequently and that this is very effective, given the time that the virus remains alive on surfaces(Groza 2020). Health authorities and different organs are reinforcing the importance of hand hygiene and care when sneezing and coughing, covering the mouth and nose with the flexed arm or elbow, or using a disposable handkerchief (Ahmed et al., 2020).

Transmission occurs from person to person, through the air, through coughing or sneezing, by touching or shaking hands or by contact with contaminated objects or surfaces, followed by contact with the mouth, nose or eyes (Groza 2020). According to the Brazilian Society of Infectious Diseases, it is not yet clear how easily the new coronavirus is transmitted from person to person. According to the World Health Organization (WHO), an individual infected with SARS-CoV-2 can generate between 1.4 and 2.5 new ones(Ahmed et al., 2020).

\section{Impacts of Fake News on General Public}

False news widely circulated on social media claims that humans can contract the new coronavirus through direct contact or eating chicken products (Roy et al., 2020). This is another piece of false information with no scientific basis: the $\gamma$-coronavirus that causes chicken infection cannot be transmitted to humans (Van Bavel et al., 2020). More needs to be pointed out that, according to a new study has been proved that even humans infected with the pathogen COVID-19, which is subordinate to the $\beta$ coronavirus of SARSCov-2, due to the coughing or sneezing and spread in the air particles cannot infect chickens. For these reasons, even if COVID-19 has become a global epidemic, as long as the conventional breeding biological regulations are followed, breeding poultry or processing poultry meat will not bring additional risks. Therefore, animal protein is still safe to eat(Ho et al., 2020; Roy et al., 2020).

African countries battling the new coronavirus face an enemy that is as hidden and dangerous as the microbes themselves: serious mistrust of the government fuels misinformation and apathy. Fake news and indifference to official warnings are becoming huge obstacles in this area. Poor medical infrastructure, sanitation facilities and crowded slums in this area provide fertile ground for the spread of Covid19(Palade et al., 2020).

African countries have begun to enforce strict rules, including imprisonment, curfew and even imprisonment for those who share false accusations. But these measures seem to be futile in preventing the spread of misinformation. The viral messages on Facebook and WhatsApp contain unfounded suggestions that gargle with vinegar can eliminate the virus, or that black people are resistant to the virus because of their skin colour. But in Africa, many claims spread in the form of private groups on the encrypted WhatsApp platform, making it more difficult to target(Palade et al., 2020; Islam et al., 2020).

In South Africa, the hardest-hit country in the region, misinformation began to spread long before the first of more than 700 cases was confirmed (Groza 2020). Many virus claims may cause harm in real life, such as using misleading coronavirus recommendations to tamper with government documents. In response to this trend, officials held regular press conferences and opened a coronavirus information website, free phone calls and WhatsApp support hotline (Pennycook et al., 2020). Opponents have tried to challenge the legislation in court, but failed. They said the legislation violated media freedom and allowed the authorities to ban critics. But the government insists that this measure is necessary to combat a large number of false claims circulating on social media(Ahmed et al., 2020). Despite increasing concerns, the fact that flights from China were still allowed to land at the beginning of the epidemic has 
exacerbated people's mistrust of the government in handling the crisis.

There is little research on the possibility of the spread of misinformation, especially during the outbreak of infectious diseases that will endanger human health. Researchers have created theoretical simulations that take into account real behavior, the spread of different diseases, incubation period and recovery time, and the speed and frequency of posting on social media and sharing real information (Poudel et al., 2020). The researchers also considered how people's distrust of traditional authority is closely related to various situations, such as the tendency to believe in conspiracy theories, the appearance of people interacting online in the "information bubble", and people are more likely to share false stories online rather than Correct information. Researchers have also studied strategies to combat false news, such as using correct information to submerge false information, and better education to make people "immune" against false information. False medical statements are the focus of attention for those seeking to minimize the potential harm of false news. Many rumours about the new crown pneumonia seem to be politically motivated (Pennycook et al., 2020; Pulido et al., 2020).

Most people, especially those who have suffered a lot from it, are not ignorant of the destructive power of fake news, but sometimes they become disseminators of fake information in a muddle(Ahmed et al., 2020). But the harm of fake news is also extraordinary, ranging from arousing controversy and affecting the reputation of others, while triggering panic and affecting social order. During the current epidemic, fake news may impact social order, challenge the bottom line of law enforcement, induce panic or confrontation, and cause the situation to deteriorate; intangible, it affects frontline morale, confuses the information market, and may cause misjudgment of the situation and lengthen the fight against the epidemic(Apuke et al., 2020).Platforms such as Facebook, WhatsApp, and many news organizations have successively published many proofreading articles in an attempt to deconstruct these network-spread articles to readers that contain many inaccurate information(Van Bavel et al., 2020).
Hedging against Fake News and its Effects

In today's era, the amount of information data is increasing, so we need to pay attention to the analysis of news information, and only in this way can we put an end to fake news. In their daily work, reporters and news editors should analyse the authenticity and reliability of information sources of news events, and improve their ability to distinguish and analyse news events. Only in this way can they improve their competitiveness ( $\mathrm{O}^{\prime}$ Connor et al., 2020). Nowadays, the speed of information dissemination is getting faster and faster, and the channels of dissemination are becoming wider and wider. People's views on different events are gradually showing a diversified development trend (Sahoo et al., 2020). News reporters should assume the role of integrating public opinion. We should publicize some positive news materials to the public, keep close to the lives of the people, and increase their enthusiasm for participation. In addition, we should continue to improve our professional quality and comprehensive quality, conduct in-depth analysis of news reports, make overall plans, think with rational thinking, and learn to dig out the valuable news information in the news to improve the visibility of news. And guarantee its authenticity (Van Bavel et al., 2020).

Fighting back against fake news can increase your visibility. Although becoming a wellknown defender of science may be good for the profession, it may also have negative effects(Apuke et al., 2020). West believes that this is very helpful for careers, especially for researchers who are new to the workplace, but it may also take days or weeks, and once invested, it is difficult to return to your research. In general, he believes that researchers should not let professional considerations become obstacles when deciding whether to help fight COVID-19 false information (Roy et al., 2020).

The elimination of fake news should improve one's own professional quality, which mainly includes two parts: professional ability and political quality. Only with solid professional knowledge can the content of the edited report cater to the psychology of the audience and convey the mainstream social values (Groza 2020). Relying on solid professional knowledge to start work can also avoid work 
mistakes to the greatest extent. Political literacy is the support point for journalists to carry out their work, and it directly determines the quality of the news content they edit. To ensure the truthfulness and objectivity of news reports, one must constantly improve one's ideological and political literacy according to the needs of actual work. Work in this area can also stifle the living space of fake news. Specifically, improving professionalism can be accomplished through training. The main body of the unit should build a communication platform for journalists, put the training in place, and create an opportunity for grassroots staff to continuously learn and progress (Groza 2020).

\section{CONCLUSION}

Overall, it can be inferred from the previous discussions regarding fake news and its impacts that there seem to be numerous implications. Fake news not only tends to generate excessive revenue through the propagation on various media networks, but also can cause harmful effects as well. In the case of the novel Covid-19 pandemic and the related myths and fake news, it is evident that the misleading information can also tend to become a source of harmful effect.

\section{REFERENCES}

Ahmed, W., Vidal-Alaball, J., Downing, J. and Seguí, F.L., 2020. COVID-19 and the 5G conspiracy theory: social network analysis of Twitter data. Journal of Medical Internet Research, 22(5), p.e19458.

Apuke, O.D. and Omar, B., 2020. Fake news and COVID-19: modelling the predictors of fake news sharing among social media users. Telematics and Informatics, p.101475.

Bonaccorsi, G., Pierri, F., Cinelli, M., Flori, A., Galeazzi, A., Porcelli, F., Schmidt, A.L., Valensise, C.M., Scala, A., Quattrociocchi, W. and Pammolli, F., 2020. Economic and social consequences of human mobility restrictions under COVID-19. Proceedings of the National Academy of Sciences, 117(27), pp.15530-15535.

Calvillo, D.P., Ross, B.J., Garcia, R.J., Smelter, T.J. and Rutchick, A.M., 2020. Political ideology predicts perceptions of the threat of covid-19 (and susceptibility to fake news about it). Social Psychological and Personality Science, p.1948550620940539.

Cinelli, M., Quattrociocchi, W., Galeazzi, A., Valensise, C.M., Brugnoli, E., Schmidt, A.L., Zola, P., Zollo, F. and Scala, A., 2020. The covid-19 social media infodemic. arXiv preprint arXiv:2003.05004.

Groza, A., 2020. Detecting fake news for the new coronavirus by reasoning on the Covid-19 ontology. arXiv preprint arXiv:2004.12330.

Ho, C.S., Chee, C. and Ho, R., 2020. Mental health strategies to combat the psychological impact of coronavirus disease 2019 (COVID-19) beyond paranoia and panic. Ann Acad Med Singapore, 49(3), pp.1-6.

Islam, M.S., Sarkar, T., Khan, S.H., Mostofa Kamal, A.H., Hasan, S.M., Kabir, A., Yeasmin, D., Islam, M.A., Amin Chowdhury, K.I., Anwar, K.S. and Chughtai, A.A., 2020. COVID-19-Related Infodemic and Its Impact on Public Health: A Global Social Media Analysis. The American Journal of Tropical Medicine and Hygiene, p.tpmd200812.

Kadam, A.B. and Atre, S.R., 2020. Negative impact of social media panic during the COVID-19 outbreak in India. Journal of Travel Medicine, 27(3), p.taaa057.

Naeem, S.B. and Bhatti, R., 2020. The Covid-19 'infodemic': a new front for information professionals. Health Information $\mathcal{E}$ Libraries Journal.

O'Connor, C. and Murphy, M., 2020. Going viral: doctors must tackle fake news in the covid-19 pandemic. bmj, 24(369), p.m1587.

Palade, I. and BALABAN, D.C., 2020. An Analysis of COVID-19-Related Fake News from Romania. A Pilot Qualitative Study. Journal of Media Research, 13(2).

Pennycook, G., McPhetres, J., Zhang, Y., Lu, J.G. and Rand, D.G., 2020. Fighting COVID-19 misinformation on social media: Experimental evidence for a scalable accuracy-nudge intervention. Psychological science, 31(7), pp.770-780. 
Poudel, K. and Subedi, P., 2020. Impact of COVID-19 pandemic on socioeconomic and mental health aspects in Nepal. International Journal of Social Psychiatry, 66(8), pp.748-755.

Pulido, C.M., Villarejo-Carballido, B., Redondo-Sama, G. and Gómez, A., 2020. COVID-19 infodemic: More retweets for science-based information on coronavirus than for false information. International Sociology,

Rovetta, A. and Bhagavathula, A.S., 2020. Covid-19-related web search behaviors and infodemic attitudes in italy: Infodemiological study. JMIR public health and surveillance, 6(2), p.e19374.

Roy, D., Tripathy, S., Kar, S.K., Sharma, N., Verma, S.K. and Kaushal, V., 2020. Study of knowledge, attitude, anxiety \& perceived mental healthcare need in Indian population during COVID-19 pandemic. Asian Journal of Psychiatry, p.102083.
Kabha, R., Kamel, A., Elbahi, M., \& Narula, S. (2019). Comparison Study between the $\mathrm{UAE}$, the UK, and India in Dealing with WhatsApp Fake News. Journal of Content, Community and Communication, 10, 176186.

Sahoo, S., Padhy, S.K., Ipsita, J., Mehra, A. and Grover, S., 2020. Demystifying the myths about COVID-19 infection and its societal importance. Asian journal of psychiatry.

Van Bavel, J.J., Baicker, K., Boggio, P.S., Capraro, V., Cichocka, A., Cikara, M., Crockett, M.J., Crum, A.J., Douglas, K.M., Druckman, J.N. and Drury, J., 2020. Using social and behavioural science to support COVID-19 pandemic response. Nature Human Behaviour, pp.1-12.

Xiong, J., Lipsitz, O., Nasri, F., Lui, L.M., Gill, H., Phan, L., Chen-Li, D., Iacobucci, M., Ho, R., Majeed, A. and McIntyre, R.S., 2020. Impact of COVID-19 pandemic on mental health in the general population: A systematic review. Journal of affective disorders. 